\title{
CO-EXISTENCE OF INTRAMUSCULAR SPINDLE CELL LIPOMA WITH AN INTRAMUSCULAR ORDINARY LIPOMA: REPORT OF A CASE
}

\author{
Aggelos Laliotis $^{1}$, Eelco De Bree ${ }^{1}$, Stavrianthi Vasilaki $^{2}$, Michael Papadakis ${ }^{3}$, John Melissas $^{1}$
}

1Department of Surgical Oncology, University Hospital Heraklion, Greece

${ }^{2}$ Radiology Department Asklipios Diagnostic Center, Greece

3 Department of Pathology, University Hospital Heraklion, Greece

\begin{abstract}
Spindle cell lipoma is a relatively rare adipocytic neoplasm, which usually occurs in the posterior neck, shoulder or upper back of male patients aged 45-65 years. We report here an unusual coexistence of ordinary and spindle cell lipoma. The patient presented with a painless mass in the area of the right scapula. Imaging was suggestive of a lipomatous mass, possibly liposarcoma. Histological examination revealed the concurrent existence of an intramuscular spindle cell lipoma and an ordinary lipo$\mathrm{ma}$. In the literature there are only fourteen cases of intramuscular spindle cell lipoma and only in four cases there was a coexisting mature lipoma. As exclusion of malignancy remains clinicians main concern,diagnosis and treatment of deep seated lipomatous tumors remains challenging
\end{abstract}

Key words: CD34, intramuscular lipoma, spindle cell lipoma.

\section{Introduction}

Spindle cell lipoma is a distinct lipoma of a small subgroup of lipomas occurring predominantly in the subcutaneous tissue of the neck, shoulder and back and was first described in 1975 [1]. It is a relatively rare variant (1.5\% of all adipocytic neoplasms), and a histologically distinct lesion characterized by the replacement of mature fat from collagen forming spindle cells and eosinophilic collagen bundles with a benign clinical course $[2,3]$. Intramuscular development of these tumors is very rare and to our knowledge only 14 cases have been reported so far [2-15]. Coexistence of intramuscular mature lipoma and spindle cell lipoma has also very rarely been reported.

\section{Case report}

A 59-year-old man presented with a 15-year history of a painless mass in the area of the right scapula which was gradually increasing in size and causing some discomfort. The patient's medical history was unremarkable. On physical examination there was a non- tender palpable mass of about $6 \mathrm{~cm} \times 5 \mathrm{~cm}$ approximately over the right scapula. Concurrent lymphadenopathy was absent.

A focused magnetic resonance imaging (MRI) showed an intramuscular well-defined, heterogenous mass, $5.3 \mathrm{~cm} \times 2.8 \mathrm{~cm} \times 4.5 \mathrm{~cm}$ in size, located within the medial part of the right latissimus dorsi muscle (Fig.1). Fatty density was only observed in its lower part, which was mildly enhanced with the administration of intravenous contrast. The imaging findings were suggestive of liposarcoma. Tru-cut biopsy was performed and the histological examination was suggestive of an atypical lipoma or well-differentiated liposarcoma. As part of sarcoma staging, a computed tomography (CT) of the chest was performed. There were no signs of metastasis, while a mass 5.5 $\mathrm{cm} \times 2.2 \mathrm{~cm}$ in size was seen under the latissimus dorsi muscle. Fatty density was prominently observed but diffuse haziness was seen within it. Another fatty density area of about $2 \mathrm{~cm}$ diameter was also demonstrated next to the medial edge of the scapula, within the rhomboideus major muscle, suggestive of a second lipomatous mass. 

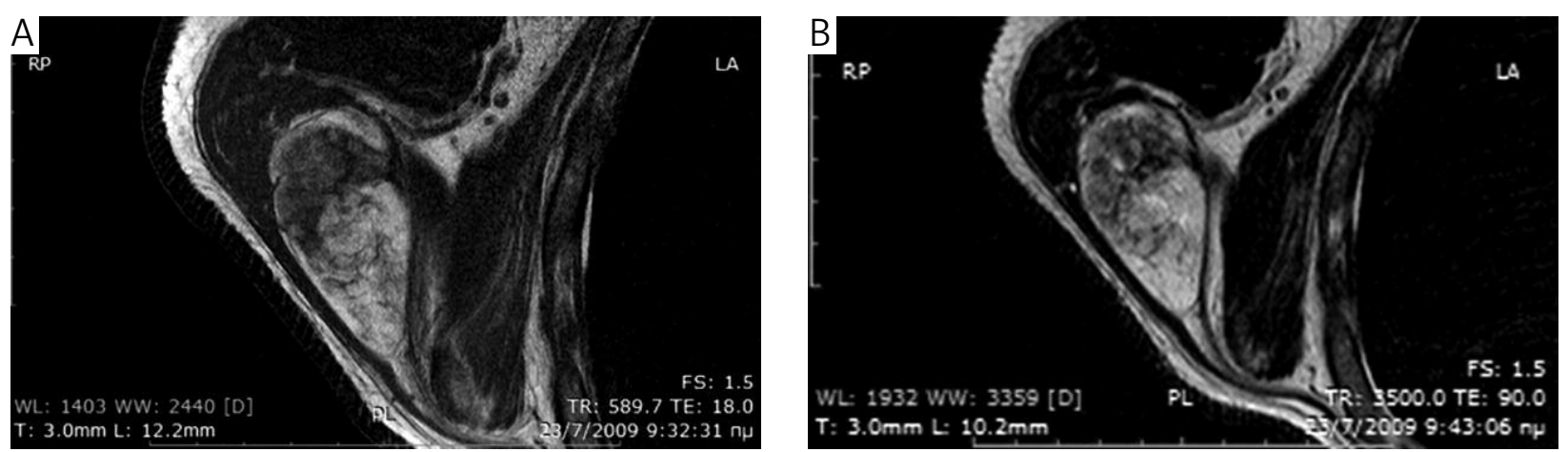

Fig. 1A,B. Soft tissue lesion within right latissimus dorsi muscle with obvious heterogeneity. The lesion shows heterogeneous signal with areas of fatty and nonadipose tissue within the same tumor

Wide excision of the mass with overlying latissimus dorsi muscle fibers was performed under general anesthesia. The postoperative course was uneventful.

Histological examination demonstrated macroscopically a well-circumscribed tumor, $9 \mathrm{~cm} \times 7.5 \mathrm{~cm}$ $\times 3.5 \mathrm{~cm}$ in size, covered by muscle fibers (Fig. 2). At microscopical examination the tumor consisted of mature fatty cells and areas of hyalinization and loose connective tissue with collagen bundles, and spindle-shaped cells presenting in it almost uniformly (Fig. 3). Presence of mast cells was not noted. Some of the spindle-shaped cells were presenting a small degree of nuclear atypia although mitoses and hyperchromatic nuclei were not present.

The cytoplasm of the spindled stromal cells was positive for CD34 immunostaining and negative for S100, MIB-1 and MDM-2. There were thick-walled

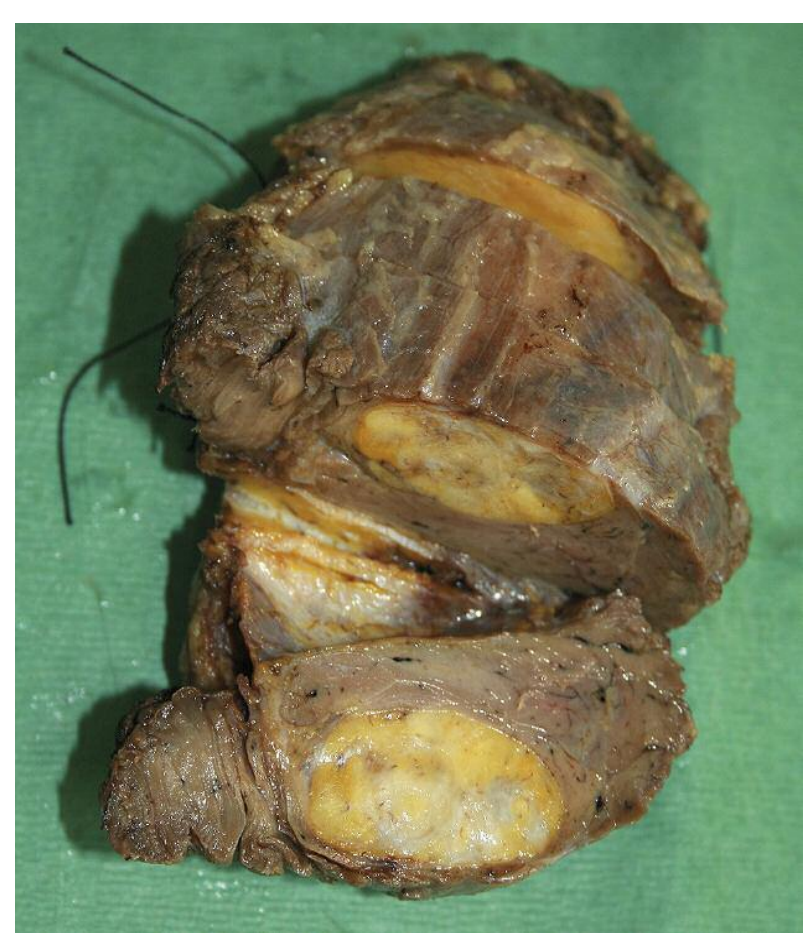

Fig. 2. Macroscopic view of the tumor covered by muscle fibers and deep fascia vessels within the stroma, with fibrosis around them and also areas of mucinous component. Lipoblasts or atypical spindle-shaped cells were not identified. The surgical margins did not show evidence of tumor invasion.

At follow-up examination, six months postoperatively, significant increase in size of the second tumor was observed. There were no signs of local recurrence of the excised spindle cell lipoma. MRI examination demonstrated a homogeneous mass of $9 \mathrm{~cm} \times 6.3 \mathrm{~cm}$ $\times 3.2 \mathrm{~cm}$ inside the right rhomboideus major muscle. Its density was consistent with fatty tissue and intravenous contrast enhancement was absent. Because of its completely benign characteristics, simple excision of the lipomatous tumor was performed. The histological examination was consistent with the diagnosis of a mature lipoma.

\section{Discussion}

Spindle cell lipomas are benign lipomatous tumors that occur predominantly in men older than 45 years. There is a striking predilection for the regions of the shoulder and posterior neck. In most cases the neoplasm

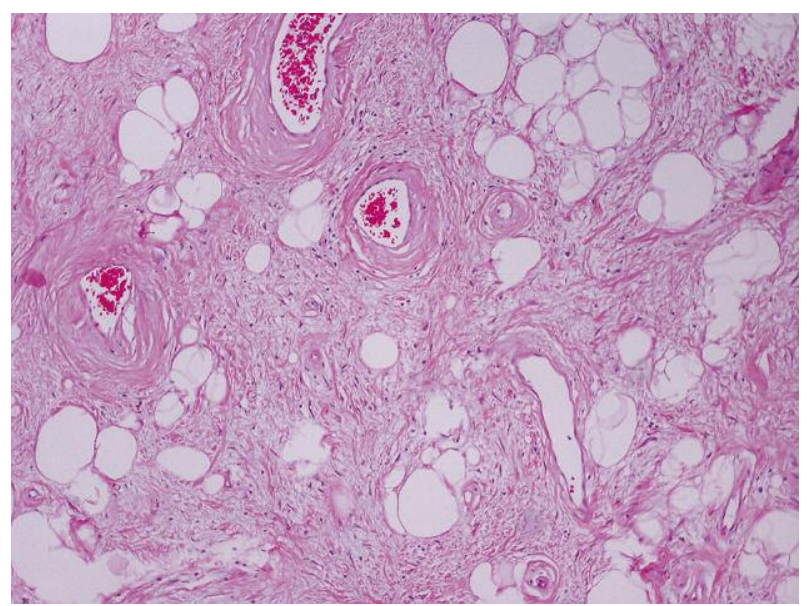

Fig. 3. Excised spindle cell lipoma tumor. Note the thick walled vessels and concentric spindle cell arrangement within collagenous stroma 
occurs in the dermis or subcutis as a single, slow growing, superficially or deeply located nodule. Intramuscular development of this tumor is noted mainly in the same regions that subcutaneous spindle cell lipomas occur. Of the 14 already published cases 8 were located in the shoulder, neck and upper back area as in our case $[3,4,6,9,11,13-15], 2$ were located in the head $[8,12], 2$ in the arm $[2,5]$ and 2 in the thigh $[7,10]$. The concurrent intramuscular existence of a spindle cell lipoma and of an ordinary lipoma is very rare and to our knowledge only four cases have been described in the literature [7, 13-15].

Uniformly homogeneous signal as well as a mass with homogeneous high T1 and T2 signal are indicative of benign fat tumor mass. Large size, heterogeneous signal, deep location and increase in diameter of soft tissue tumors are commonly associated with increased risk of malignancy $[16,17]$. Generally, the development of deep seated lipomatous tumors is rare. They are divided into those arising intramuscularly (infiltrative and well circumscribed) and those developing intermuscularly and comprise respectively only 1.8 and $0.3 \%$ of all fatty tumors. The risk of recurrence is higher than in the case of a typical lipoma. Sometimes recurrence is due to inadequate excision associated with difficulties in surgical accessing of the tumor $[18,19]$. The increased recurrence rate and their usually large size, raise the suspicion of a possible liposarcoma.

The contribution of imaging methods to establish the diagnosis of spindle cell lipoma is limited. MRI remains the imaging method of choice. Like most other musculoskeletal tumors, spindle cell lipomas display a spectrum of features that may overlap with those of liposarcomas making an adequate diagnosis impossible [20]. The definite diagnosis is provided by histological examination of the tumor.

The existence of spindle-shaped fibroblast-like cells with long polar cytoplasmic extensions, separated by amorphous ground substance and bundles of collagen, associated with several large, uniloculated fat cells is characteristic for spindle cell lipomas [1]. It is interesting that liposarcomas may have areas resembling spindle cell lipomas and thus lesions must be extensively sampled to rule out malignancy [21].

The existence of a rare reported variant called spindle cell liposarcoma characterized by areas of mature fat, spindle cells, fibrous tissue, myxoid stroma and focal nuclear pleomorphism make the differential diagnosis more challenging. In all these cases there were scattered lipoblasts, an adipocytic component that varied in cell size and shape with nuclear hyperchromasia and some had local recurrence, dedifferentiation and metastasis [22]. Several morphological subtypes of spindle cell lipoma have been described. Cutaneous spindle cell/pleomorphic lipoma is mainly presented as a poorly circumscribed dermal nodule primarily affecting females. The angiomatous variant is characterized by the presence of endothelial lined spaces within the lesion, while in the fibrous variant the presence of dense fibrous stroma is the major component of the lesion. Finally, dendritic fibromyxolipoma is another spindle cell lipoma subtype in which a myxoid stroma can predominate and the spindle cells can display dendritic processes [11, 23-28].

Moreover the presence of CD34 immunoreactivity is characteristic, especially in the absence of S100 expression. Desmin, factor XIIIa, Bcl-2 and androgen receptor are also present in these tumors in contrast to S100, actin and factor VIII. The absence of immunoreactivity for Ki-67 is suggestive of a non-aggressive tumor. Nevertheless, immunoreactivity for $\mathrm{CD}$ 34 which is present in a wide variety of unusual soft tissue tumours is very intense in the spindle cell component of spindle cell lipoma. The presence of a CD34 positive dendritic spindle cells that expand or exhibit overgrowth may account for the distinctive histologic appearance of the lesion. This fact may suggest that spindle cell lipoma possibly represents a dendritic interstitial cell neoplasm located within fat and not a true lipomatous tumor $[12,29,30]$.

In addition, genetic background plays a very important role. More specifically, Fletcher et al. [31], found that all cases included in their study showed karyotypic abnormalities. Aberrations involving the 16q chromosome were present in 7 out of 8 cases, 5 out of 8 were also combined with unbalanced aberrations of the $13 \mathrm{q}$ chromosome, while 1 case showed simultaneous $13 \mathrm{q}$ abnormality and a ring chromosome. The reliable correlation between cytogenetic abnormalities and morphologic subtype in lipomatous tumors can be of diagnostic value in histologically borderline or difficult cases [31].

The synchronous presence of a deep seated ordinary lipoma with a spindle cell lipoma is very rare. The theory that mast cells stimulate proliferation of few CD34 positive spindle cells present in ordinary lipomas and therefore the conversion of an ordinary lipoma to a spindle cell lipoma, has not been confirmed [13]. In our case we did not notice the presence of mast cells in any of the examined specimens. Nevertheless, such a possibility cannot be generally excluded and remains to be clarified in a series of patients with concurrent presence of such tumors.

In conclusion, we have reported a case of coexistence of intramuscular mature lipoma and spindle cell lipoma. Diagnosis and treatment of deep seated lipomatous tumors remains challenging. Rarely, they can also be found in unusual sites, such as the orbit [32]. Exclusion of malignancy remains clinicians' main concern. Although deep location of soft tissue tumors, large size and heterogeneity at imaging are associated with an increased risk of malignancy, benign spindle cell lipoma should be included in differential diagnosis. 


\section{References}

1. Enzinger FM, Harvey DA. Spindle cell lipoma. Cancer 1975 36: 1852-1859.

2. Fletcher CD, Martin-Bates E. Spindle cell lipoma: a clinicopathological study with some original observations. Histopathology 1987; 11: 803-817.

3. Horiuchi K, Yabe H, Nishimoto K, et al. Intramuscular spindle cell lipoma: Case report and review of the literature. Pathol Int 2001; 51: 301-304.

4. Angervall L, Dahl I, Kindblorn LG, et al. Spindle cell lipoma. APMIS 1976; 84: 477-487.

5. Jensen ML, Nielsen VT. Intramuscular (subfascial) vascular spindle cell lipoma. A case report. Tumori 1990; 76: 616-619.

6. Sund S, Hordvik M, Maehle B, et al. Large intramuscular spindle-cell lipoma. With review of the literature. A case report. APMIS 1988; 96: 347-351.

7. Usta U, Türkmen E, Mizrak B, et al. Spindle cell lipoma in an intramuscular lipoma. Pathol Int 2004; 54: 734-739.

8. Agoff SN, Folpe AL, Grieco VS, et al. Spindle cell lipoma of the oral cavity. Report of a rare intramuscular case with fine needle aspiration findings Acta Cytol 2001; 45: 93-98.

9. Williams MD, Howlett DC, Violaris N, et al. Intramuscular spindle cell lipoma of the sternomastoid muscle - imaging and pathological appearances. J Diagn Radiography Imaging 2006; 6: 43.

10. Bancroft LW, Kransdorf MJ, Peterson JJ, et al. Imaging characteristics of spindle cell lipoma. Am J Roentgenol 2003; 181: 1251-1254.

11. Karim RZ, McCarthy SW, Palmer AA, et al. Intramuscular dendritic fibromyxolipoma: myxoid variant of spindle cell lipoma? Pathol Int 2003; 53: 252-258.

12. Mandal RV, Duncan LM, Austen WG Jr, et al. Infiltrating intramuscular spindle cell lipoma of the face. J Cutan Pathol 2009; 36: $70-73$.

13. Sakai H, Kuroda K, Hara D, et al. Coexistence of spindle cell lipoma and ordinary lipoma J Dermatol 2004; 31: 831-834.

14. Siddiqui M, Su L, Michael CW. Synchronous ordinary lipoma and spindle cell lipoma diagnosed by fine needle aspiration. Diagn Cytopathol 2006; 34: 455-456.

15. Turhan-Haktanir N, Demir Y, Aycicek A. Concurrent large spindle cell and ordinary lipomas. J Craniofac Surg 2007; 18: 1193-1195.

16. Rydholm A. Management of patients with soft-tissue tumors. Strategy developed at a regional oncology center. Acta Orthop Scand Suppl 1983; 203: 13-77.

17. Rougraff BT, Durbin M, Lawerence J, et al. Histologic correlation with magnetic resonance imaging for benign and malignant lipomatous masses. Sarcoma 1997; 1: 175-179.

18. Fletcher CD, Martin-Bates E. Intramuscular and intermuscular lipoma: neglected diagnoses Histopathology 1988; 12: 275-287.

19. Evans HL. Liposarcoma: a study of 55 cases with a reassessment of its classification. Am J Surg Pathol 1979; 3: 507-523.

20. Rosen EL, Baker JA, Soo MS. Accuracy of a collagen-plug biopsy site marking device deployed after stereotactic core needle breast biopsy. AJR Am J Roentgenol 2003; 181: 1295-1299.

21. Kindblom LG, Angervall L, Jarlstedt J. Liposarcoma of the neck: a clinicopathologic study of 4 cases. Cancer 1978; 42: 774-780.

22. Dei Tos AP, Mentzel T, Newman PL, et al. Spindle cell liposarcoma, a hitherto unrecognized variant of liposarcoma. Analysis of six cases. Am J Surg Pathol 1994; 18: 913-921.

23. French CA, Mentzel T, Kutzner $\mathrm{H}$, et al. Intradermal spindle cell/pleomorphic lipoma: a distinct subset. Am J Dermatopathol 2000; 22: 496-502.

24. Zelger BW, Zelger BG, Plörer A, et al. Dermal spindle cell lipoma: plexiform and nodular variants. Histopathology 1995; 27 : 533-540.

25. Duve S, Müller-Höcker J, Worret WI. Spindle-cell lipoma of the skin. Am J Dermatopathol 1995; 17: 529-533.
26. Zamecnik M, Michal M. Angiomatous spindle cell lipoma: Report of three cases with immunohistochemical and ultrastructural study and reappraisal of former 'pseudoangiomatous' variant. Pathol Int 2007; 57 : 26-31.

27. Diaz-Cascajo C, Borghi S, Weyers W. Fibrous spindle cell lipoma: report of a new variant. Am J Dermatopathol 2001; 23: 112-115.

28. Suster S, Fisher C, Moran CA. Dendritic fibromyxolipoma: clinicopathologic study of a distinctive benign soft tissue lesion that may be mistaken for a sarcoma. Ann Diagn Pathol 1998; 2: 111-120.

29. Suster S, Fisher C. Immunoreactivity for the human hematopoietic progenitor cell antigen (CD34) in lipomatous tumors. Am J Surg Pathol 1997; 21: 195-200.

30. Silverman JS, Tamsen A. Fibrohistiocytic differentiation in subcutaneous fatty tumors. Study of spindle cell, pleomorphic, myxoid, and atypical lipoma and dedifferentiated liposarcoma cases composed in part of CD $34+$ fibroblasts and FXIIIa+ histiocytes. J Cutan Pathol 1997; 24: 484-893.

31. Fletcher CD, Akerman M, Dal Cin P, et al. Correlation between clinicopathological features and karyotype in lipomatous tumors. A report of 178 cases from the Chromosomes and Morphology (CHAMP) Collaborative Study Group. Am J Pathol 1996; 148: 623-630.

32. Ulivieri S, Olivieri G, Motolese PA, et al. Spindle cell lipoma of the orbit: a case report of an unusual orbital pathology. Neurol Neurochir Pol 2010; 44: 419-423.

\section{Address for correspondence}

\section{Aggelos Laliotis MD}

Department of Surgical Oncology

University Hospital of Heraklion

Crete, Greece

tel. +306944303294

fax +302810392382

e-mail: laliotisac@gmail.com 